\title{
Omega-3 Fatty Acid Supplementation Prevents Hepatic Steatosis in a Murine Model of Nonalcoholic Fatty Liver Disease
}

\author{
IAN P.J. ALWAYN, KATHLEEN GURA, VÂNIA NOSÉ, BLANCA ZAUSCHE, PATRICK JAVID, \\ JENNIFER GARZA, JENNIFER VERBESEY, STEPHAN VOSS, MARIO OLLERO, \\ CHARLOTTE ANDERSSON, BRUCE BISTRIAN, JUDAH FOLKMAN, AND MARK PUDER
}

\author{
Departments of Surgery and the Vascular Biology Program [I.P.J.A., P.J., J.G., J.V., J.F., M.P.], Clinical \\ Pharmacy [K.G.], Pathology [V.N.], and Radiology [B.Z.S.V.], The Children's Hospital, and Department \\ of Medicine [M.O., C.A.] and Laboratory of Nutrition and Infection [B.B.], Beth Israel Deaconess \\ Medical Center, Harvard Medical School, Boston, MA 02115
}

\begin{abstract}
ABST
Prolonged use of total parenteral nutrition can lead to nonal-
coholic fatty liver disease, ranging from hepatic steatosis to
cirrhosis and liver failure. It has been demonstrated that omega-3
fatty acids are negative regulators of hepatic lipogenesis and that
they can also modulate the inflammatory response in mice.
Furthermore, they may attenuate hepatic steatosis even in leptin-
deficient ob/ob mice. We hypothesized that omega-3 fatty acid
supplementation may protect the liver against hepatic steatosis in
a murine model of parenteral nutrition in which all animals
develop steatosis and liver enzyme disturbances. For testing this
hypothesis, groups of mice received a fat-free, high-carbohydrate
liquid diet ad libitum for $19 \mathrm{~d}$ with enteral or i.v. supplementation
of an omega-3 fatty acid emulsion or a standard i.v. lipid
emulsion. Control mice received food alone or the fat-free,
high-carbohydrate diet without lipid supplementation. Mice that
received the fat-free, high-carbohydrate diet only or supple-
\end{abstract}
mented with a standard i.v. lipid emulsion developed severe liver damage as determined by histology and magnetic resonance spectroscopy as well as elevation of serum liver function tests. Animals that received an i.v. omega-3 fatty acid emulsion, however, showed only mild deposits of fat in the liver, whereas enteral omega-3 fatty acids prevented hepatic pathology and led to normalization of liver function tests. In conclusion, whereas standard i.v. lipid emulsions fail to improve dietary-induced steatotic injury to the liver, i.v. supplementation of omega-3 fatty acids partially and enteral supplementation completely protects the liver against such injury. (Pediatr Res 57: 445-452, 2005)

Abbreviations
HCD, fat free, high carbohydrate diet
MRS, magnetic resonance spectroscopy
O3FA, omega-3 fatty acid

Nonalcoholic fatty liver disease consists of a variety of pathologic states ranging from the simple buildup of fat in the liver (hepatic steatosis) to nonalcoholic steatohepatitis, cirrhosis, and ultimately liver failure (1-4). Nonalcoholic fatty liver disease is being increasingly appreciated as a major cause of liver-related morbidity and mortality. A recent survey indicated that nonalcoholic fatty liver disease may account for $\sim 80 \%$ of individuals with elevated serum liver enzymes (5) and further that up to $30 \%$ of the Western population may have nonalcoholic fatty liver disease (6). Furthermore, nonalcoholic fatty liver disease is associated with metabolic disorders such

Received May 4, 2004; accepted August 16, 2004.

Correspondence: Mark Puder, M.D., Ph.D., Department of Surgery, New Research Building 11.120, Children's Hospital Boston, 300 Longwood Avenue, Boston, MA 02115; e-mail: mark.puder@tch.harvard.edu.

IPJA was supported by the Dutch Cancer Society. MP was supported by the Garrett Smith Foundation and CHMC Surgical Foundation.

DOI: 10.1203/01.PDR.0000153672.43030.75 as obesity (7-9) and diabetes (10), as well as with prolonged chemotherapy $(11,12)$ and total parenteral nutrition $(13-17)$. In fact, liver injury related to total parenteral nutrition is one of the major causes of liver injury in premature children $(18,19)$.

Several hypotheses have been proposed to explain the pathogenesis of nonalcoholic fatty liver disease, although none have been conclusive. The most accepted theory is the "two hit" hypothesis, in which the first hit involves the development of hepatic steatosis, rendering the liver more susceptible to a second, as yet undefined, hit, resulting in more severe liver damage. The development of hepatic steatosis results from an imbalance in the rates of entry, synthesis, or clearance of fat from the liver (20). More specific, the hepatic uptake of fatty acids and triglycerides and their rates of synthesis, the secretion of these compounds via plasma or bile, or the hydrolysis of triglycerides or oxidation of fatty acids may be altered (21). These mechanisms may also be important in the development of hepatic steatosis as a result of the prolonged use of total 
parenteral nutrition, as some investigators have proposed that deficiencies or toxicities of the parenteral nutrition solution may lead to hepatic injury (22-24).

Since the mid-1980s, a renewed interest in omega-3 fatty acids (O3FAs) led to consideration of their role in the cause and management of diverse diseases such as psychiatric (2527 ) and cardiovascular disorders $(28,29)$, inflammatory bowel disease (30), and cystic fibrosis (31). The O3FAs, present in fish oil, interfere with the arachidonic acid pathway of inflammation (32) and can also modulate the response of macrophages to endotoxin by inhibition of TNF- $\alpha$ production in vitro $(33,34)$. Dietary O3FAs can decrease IL-6 and other proinflammatory cytokine levels as well, both in vitro and in vivo (35-37). Furthermore, O3FAs have been shown to accelerate the clearance of chylomicron triglycerides in humans, thus effectively reducing triacylglycerol concentrations in serum in vivo (38). Moreover, it has been demonstrated that i.v. administration of fish oil reduces parenteral nutrition-induced cholestasis in newborn piglets (39) and rats $(40,41)$ and that dietary omega-3 and omega-6 polyunsaturated fatty acids can regulate hepatic lipogenesis by reducing sterol regulatory element-binding protein-1 in the liver (42). Finally, a recent clinical study that compared 19 patients who had nonalcoholic fatty liver disease with 11 normal control subjects revealed that patients with nonalcoholic fatty liver disease had a higher ratio of long-chain polyunsaturated fatty acids omega-6/omega-3 in their livers than did control subjects (43).

These findings provide the rationale for undertaking the experiments to test the hypothesis that supplementation of O3FAs could attenuate fatty liver changes in a novel murine model of hepatic steatosis that mimics the effects of total parenteral nutrition. Furthermore, we were interested in comparing O3FA supplementation with a standard lipid emulsion that is commonly administered with parenteral nutrition to provide additional calories and prevent essential fatty acid deficiency. Other investigators have shown that the lipid emulsions used in parenteral nutrition may in fact be associated with the development of hepatic steatosis (44). In this model, mice that have exclusive ad libitum access to a fat-free liquid diet that contains $20 \%$ dextrose develop hepatic steatosis within $19 \mathrm{~d}$ in conjunction with essential fatty acid deficiency (45). Hepatic changes are characterized by the development of diffuse macro- and microvesicular steatosis seen predominantly in the periportal and midzone hepatocytes by histology and elevated serum alanine aminotransferase and aspartate aminotransferase levels. In this study, we demonstrate that i.v. and enteral supplementation of O3FAs can indeed prevent dietary-induced hepatic steatosis in mice, whereas i.v. supplementation of a conventional lipid emulsion that is commonly used in total parenteral nutrition fails to improve hepatic steatosis.

\section{METHODS}

Animal model. Experiments were performed on 6- to 8-wk-old C57BL6 mice (Taconic, Germantown, NY). The animals, in groups of five, were housed in a barrier room and were acclimated to their environment for at least $72 \mathrm{~h}$ before the initiation of each experiment. Animal protocols complied with the National Institutes of Health Animal Research Advisory Committee guidelines and were approved by the Children's Hospital Boston Animal Care and Use Committee. The animals were weighed every third day, and at the time when the animals were killed, each group of mice consisted of five animals.

Diet and experimental groups. Experimental mice had exclusive ad libitum access to a liquid fat-free, high-carbohydrate diet (HCD) identical to the parenteral nutrition solution used at Children's Hospital, Boston. This solution contains $20 \%$ dextrose, a commercial mixture of $2 \%$ essential and nonessential amino acids (TrophAmine; B. Braun Medical, Irvine, CA), $0.2 \%$ pediatric trace elements (American Regent, Shirley, NY), 0.5\% pediatric multivitamins (MVI Pediatric; aaiPharma, Wilmington, NC), $30 \mathrm{mEq}$ of sodium, $20 \mathrm{mEq}$ of potassium, $15 \mathrm{mEq}$ of calcium (as gluconate), $10 \mathrm{mEq}$ of magnesium, $10 \mathrm{mM}$ of phosphate, $5 \mathrm{mEq}$ of acetate, and $30 \mathrm{mEq}$ of chloride per liter.

The control animals received standard rodent diet and water ad libitum. All animals in the experimental groups were fed the experimental HCD ad libitum placed in one bottle per cage. No additional sources of nutrition or hydration were provided for these animals. The bottles with the HCD were replaced daily to minimize bacterial contamination.

One group of animals received HCD without other supplements (HCDonly) for $19 \mathrm{~d}$. A second group of animals additionally received O3FAs as a commercial lipid emulsion (Omegaven; Fresenius Kabi Deutschland GmbH, Neufahrn, Germany) via orogastric gavage at $600 \mu \mathrm{L}$ every other day (HCD + O3FA-oral). This dose $(2.4 \mathrm{~g}$ of fat $/ \mathrm{kg}$ body weight of fish oil) contains 7.5-16.9 mg of omega-3 eicosapentaenoic acid and 8.6-18.5 mg of omega-3 docosahexaenoic acid. A third group of animals were similar to $\mathrm{HCD}+\mathrm{O} 3 \mathrm{FA}-$ oral but received the same dose of O3FA i.v. (HCD+O3FA-iv). A final group of animals (HCD+LIP-iv) received HCD for $19 \mathrm{~d}$ supplemented by $600 \mu \mathrm{L}$ every other day ( $4.8 \mathrm{~g}$ of fat $/ \mathrm{kg}$ body weight) of a standard i.v. lipid emulsion (20\% Intralipid; Baxter Healthcare/Fresenius Kabi Clayton LP, Clayton, NC).

Specimen collection. At $19 \mathrm{~d}$, mice were anesthetized with $300 \mu \mathrm{L}$ of $2.5 \%$ Avertin (Tribromoethanol; Sigma Chemical Co.-Aldrich Corp., St. Louis, MO) by i.p. injection. Approximately $400 \mu \mathrm{L}$ of blood was collected from each mouse via retro-orbital puncture. The specimens then were placed into serum separator tubes (Becton Dickinson, Franklin Lakes, NJ) and centrifuged at $4^{\circ} \mathrm{C}$ at $8000 \mathrm{rpm}$ for $10 \mathrm{~min}$ to collect serum. Serum was frozen at $-80^{\circ} \mathrm{C}$ and delivered to the Clinical Laboratory at Children's Hospital for measurement of aspartate aminotransferase, alanine aminotransferase, alkaline phosphatase, and total and direct bilirubin levels. A fatty acid profile was also obtained from these samples as described below.

Animals underwent a midline laparotomy to observe, excise, and weigh the liver. Approximately one half of the liver was fixed in $10 \%$ formalin overnight, washed with PBS, and then embedded in paraffin. After 5- $\mu \mathrm{m}$ sections were cut, slides were stained at the Harvard Rodent Pathology Facility and the Department of Pathology, Children's Hospital Boston with hematoxylin and eosin to examine cellular architecture and lipid accumulation and with periodic acid-Schiff (PAS) to identify the presence of glycogen.

Another portion of the liver was collected as frozen sections, placed in embedding medium (Optimal Cutting Temperature OCT; Sakura Fenetek, Torrance, CA), and promptly immersed in liquid nitrogen. A last portion was immediately snap-frozen in liquid nitrogen and placed on dry ice for future fatty acid analysis. The samples were stored at $-80^{\circ} \mathrm{C}$. Sections were stained at the Harvard Rodent Pathology Facility and the Department of Pathology, Children's Hospital Boston with Oil Red "O" to visualize hepatic fat.

Magnetic resonance imaging. The remaining liver was snap-frozen and stored at $-80^{\circ} \mathrm{C}$ for evaluation by magnetic resonance spectroscopy (MRS) to determine percentage of liver fat content. MR imaging and MRS were performed on a Bruker 8.5 T magnet. The liver samples were thawed at room temperature $1 \mathrm{~h}$ before the MR analyses. Spin-lattice relaxation time T1 measurements were made with the saturation recovery approach using spin echo images with a TE of $6.4 \mathrm{~ms}$ and 8 TRs ranging from 0.05 to $4000 \mathrm{~ms}$. Three 2-mm-thick slices were imaged for each sample, and the saturation recovery curves were generated from signal intensities measured in identically sized regions of interest within a given slice. Care was taken to exclude macroscopic fat from the selected region of interest. Free induction decays with 1024 time points and a $5-\mathrm{kHz}$ bandwidth were also acquired from each sample using a hard $90^{\circ}$ radiofrequency pulse with 16 signal averages, a 10 -s $\mathrm{TR}$, and a flip angle of $90^{\circ}$. Spectra were obtained following Fourier transformation and phasing, and percentage of fat content was determined relative to water by numerical integration of the areas under the lipid and water peaks by an independent, blinded reviewer.

Fatty acid analysis. Each serum sample $(45 \mu \mathrm{L})$ was diluted to $0.5 \mathrm{~mL}$ in PBS before lipids were extracted with 6 volumes of chloroform-methanol $(2: 1$, $\mathrm{vol} / \mathrm{vol}$ ) and centrifuged at $800 \times g$ for $3 \mathrm{~min}$, and the resulting lower phase was aspirated. Heptadecanoic acid was added to all samples as an internal standard in the form of triheptadecanoyl glycerol and diheptadecanoyl phosphatidylcholine [30 $\mu \mathrm{g}$ of each, from chloroform:methanol $(1: 1, \mathrm{vol} / \mathrm{vol})$ stock solutions; Nu-Chek Prep, Elysian, MN] before extraction. Lipid extracts from the different sample preparations were fractionated into triglycerides and 
phospholipids by solid-phase chromatography using an aminopropyl column, as described elsewhere (46). The resulting fractions were evaporated to dryness under nitrogen. Fatty acids were transmethylated by alkaline methanolysis using the $\mathrm{BF}_{3}$ reagent kit (Supelco, Bellefonte, PA). Dry fractions were resuspended in $0.5 \mathrm{~mL}$ of methanolic-base and incubated at $100^{\circ} \mathrm{C}$ for $3 \mathrm{~min}$, followed by addition of boron trifluoride-methanol $(0.5 \mathrm{~mL})$, incubation at $100^{\circ} \mathrm{C}$ for $1 \mathrm{~min}$, addition of hexane $(0.5 \mathrm{~mL})$, incubation at $100^{\circ} \mathrm{C}$ for $1 \mathrm{~min}$, and addition of $6.5 \mathrm{~mL}$ of saturated $\mathrm{NaCl}$. Samples were centrifuged at $800 \times$ $g$ for $4 \mathrm{~min}$. The hexane upper layer was transferred to a new glass tube, and an aliquot was injected in a Hewlett Packard 5890A gas chromatograph. A Supelcowax column of 30-m length and $0.5-\mathrm{mm}$ internal diameter was used. Initial temperature was $150^{\circ} \mathrm{C}$, and final temperature was $260^{\circ} \mathrm{C}$. FID temperature was $300^{\circ} \mathrm{C}$, and the total running time was 27 min. Fatty acid methyl ester peaks were identified by comparison of retention times of standard mixtures (Nu-Chek-Prep) and quantified in comparison with the internal standard (methylheptadecanoate) detector response. Mouse livers were homogenized in PBS by sonication, and the lipid fraction was extracted by addition of 6 volumes of chloroform-methanol $(2: 1, \mathrm{vol} / \mathrm{vol})$. The subsequent processing for fatty acid profiling was performed as for blood serum.

Statistical analysis. Comparisons of means between two experimental groups were made using two-tailed, independent $t$ tests. Comparisons between multiple experimental groups were performed using a one-tailed, ANOVA test. $p<0.05$ was considered statistically significant. All statistical tests were performed using SigmaStat (SPSS, Chicago, IL). Values are listed as mean \pm SEM.

\section{RESULTS}

Animal and macroscopic liver findings. All animals survived the protocol, and no animal had any signs of morbidity. All experimental groups gained weight on the HCD after $19 \mathrm{~d}$ (data not shown). There were no statistically significant differences in animal weights among experimental groups.

When the animals were killed, livers from the groups that were supplemented with O3FAs (i.v. and oral) had a similar macroscopic appearance as those of the control animals. Livers from HCD-only and HCD+LIP-iv groups, however, were pale yellow, suggesting fatty liver changes. There were no significant differences in liver weights between groups (data not shown).

Histology. A pathologist who was blinded to the groups performed histologic evaluation of the livers. There were no signs of steatohepatitis, as we did not observe any acute inflammatory changes in the experimental groups on hematoxylin and eosin sections.

Figure 1 presents histologic results from all groups. Control mice (standard diet fed) showed normal hepatic architecture (Fig. 1A) and glycogen storage patterns (Fig. 1B), without evidence of hepatic steatosis (Fig. $1 A-C$ ). In contrast, livers from HCD-only mice had diffuse macro- and microvesicular steatosis. These changes were most marked (black arrow) in the periportal and midzone hepatocytes (Fig. $1 D-F$ ). Central vein hepatocytes were spared of steatosis for a two- to threecell layer; cells outside this perimeter, however, showed an abrupt change to steatosis (red arrow). HCD-only livers revealed minimal PAS positivity in these sections, indicating minor glycogen storage (Fig. 1E). Most of the PAS-positive cells were present in a two- to three-cell layer around the central vein (green arrow). HCD+O3FA-oral livers had wellpreserved hepatic architecture with only rare microvacuoles in the cytoplasm of midzone hepatocytes (Fig. $1 G$ and $I$ ). PAS staining was strongly positive, finely granular, and diffuse but most prominent within hepatocytes around the portal and central vein regions and less prominent in the midzone (Fig.
$1 H)$. HCD + O3FA-iv livers had minimal microvesicular steatosis in midzone hepatocytes (Fig. $1 J-L$ ), and there was positive PAS staining (Fig. $1 K$ ), albeit to a lesser extent than HCD + O3FA-oral livers. HCD+LIP-iv livers had severe macro- and microvesicular steatosis (Fig. $1 M-O$ ) that, in contrast to HCD-only livers, included the central vein hepatocytes with minimal glycogen storage.

Serum liver function tests. Serum liver function tests were obtained as an additional marker of liver injury. The results for these tests are summarized in Table 1. Values obtained from control standard diet-fed mice were considered to be within the normal range. The levels of aspartate aminotransferase, alanine aminotransferase, and total bilirubin were significantly higher in the HCD-only animals $(109.0 \pm 6.4 \mathrm{U} / \mathrm{L}, 71.6 \pm 8.2 \mathrm{U} / \mathrm{L}$, and $0.20 \pm 0.00 \mathrm{mg} / \mathrm{dL}$, respectively) compared with controls $[72.2 \pm 5.5 \mathrm{U} / \mathrm{L}(p \leq 0.01) ; 48.2 \pm 3.6 \mathrm{U} / \mathrm{L}(p \leq 0.05)$; and $0.10 \pm 0.02 \mathrm{mg} / \mathrm{dL}(p \leq 0.05)$, respectively]. It is interesting that both aspartate aminotransferase $(53.0 \pm 5.8 \mathrm{U} / \mathrm{L})$ and alanine aminotransferase $(23.0 \pm 2.6 \mathrm{U} / \mathrm{L})$ values in the $\mathrm{HCD}+\mathrm{O} 3 \mathrm{FA}$-oral-treated animals were significantly lower than in control animals ( $p \leq 0.05$ and $p \leq 0.01$, respectively) and HCD-only animals $(p \leq 0.01)$. In addition, alkaline phosphatase levels were significantly decreased in the HCD +O3FA-oral $(81.8 \pm 7.2 \mathrm{U} / \mathrm{L})$ mice compared with control animals $(113.2 \pm 4.2 \mathrm{U} / \mathrm{L} ; p \leq 0.01)$ and HCD-only animals $(126.0 \pm 5.9 \mathrm{U} / \mathrm{L} ; p \leq 0.01)$. The serum liver function tests of the HCD+O3FA-iv or HCD+LIP-iv animals were not different from control animals or HCD-only animals except for total bilirubin levels of HCD+O3FA-iv animals $(0.12 \pm 0.02$ $\mathrm{mg} / \mathrm{dL}$ ). These were significantly lower than in HCD-only mice $(p \leq 0.05)$.

Radiologic fat measurements. To quantify changes in hepatic fat content, we studied livers with MRS. Livers of control mice that received only standard diet were used as a baseline with which all groups were compared. There was a close correlation between the percentage of fat calculated from the MRS data and degree of T1 shortening determined from the T1 relaxation curves (data not shown). Liver fat content values for all experimental groups are demonstrated in Fig. 2.

The liver fat content for control mice was $3.4 \pm 0.6 \%$. Animals that were fed HCD-only showed a significant increase in liver fat content to $24.1 \pm 1.7 \%(p \leq 0.001)$. HCD +O3FAoral and HCD + O3FA-iv mice had a liver fat content of $7.2 \pm$ 0.4 and $9.2 \pm 0.6 \%$, respectively. These values all are significantly lower than in HCD-only animals $(p \leq 0.01)$ but significantly higher than in control mice $(p \leq 0.05$ and $p \leq 0.001$, respectively). Livers from HCD+LIP-iv mice had a fat content of $21.0 \pm 2.5 \%$; this was not different from HCD-only mice but was significantly higher than in control animals $(p \leq 0.05)$ and O3FA-oral- and O3FA-iv-supplemented animals $(p \leq$ $0.01)$.

Fatty acid analysis. A comprehensive analysis of fatty acid composition of serum and livers was performed; the results are summarized in Table 2. As expected, animals that were fed HCD-only were essential fatty acid deficient, whereas all other animals, including HCD+LIP-iv, were not. Essential fatty acid deficiency is generally characterized as a serum Mead acid $(20: 3 \mathrm{n}-9)$ to arachidonic acid (20:4 n-6) serum triglyceride 

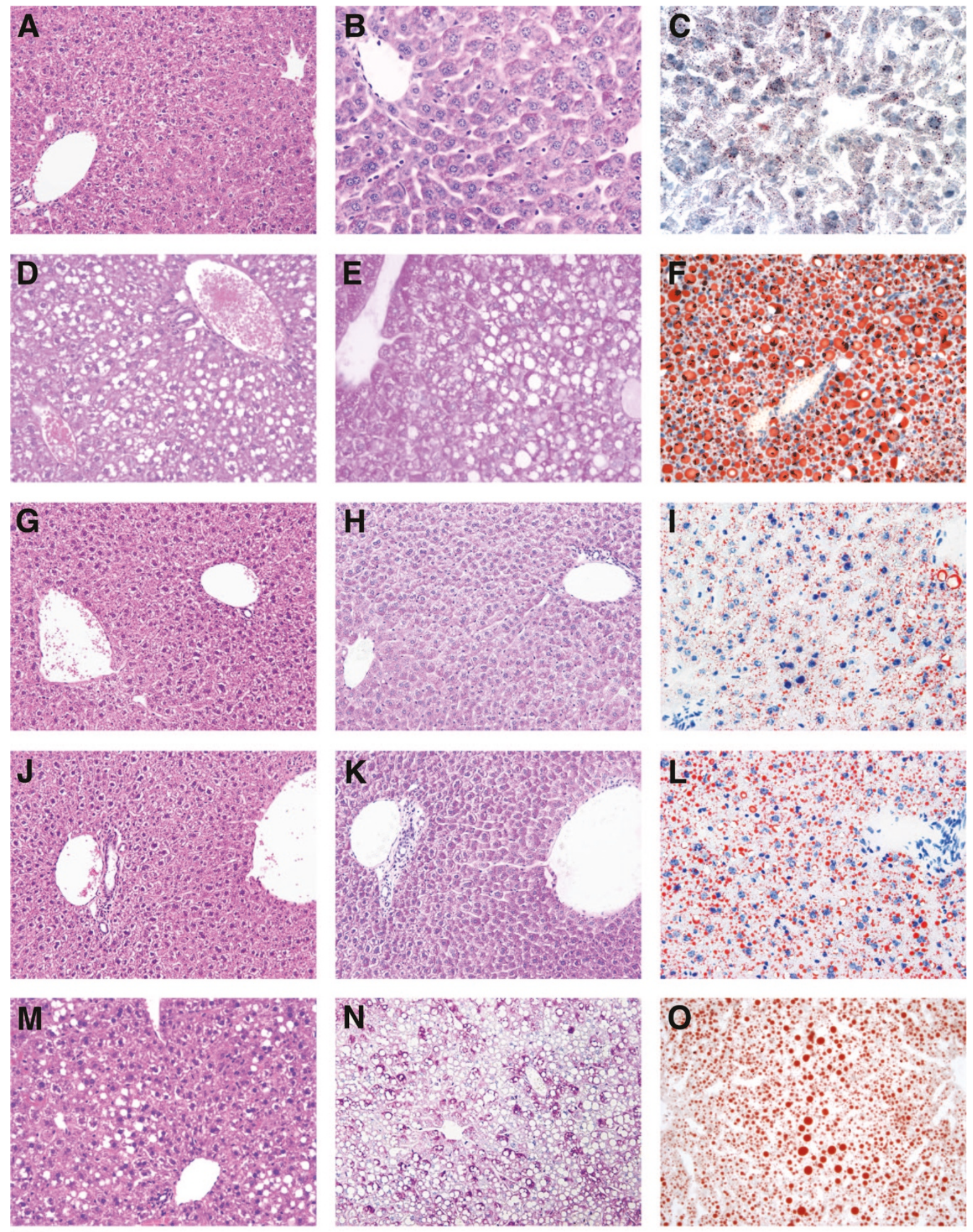

Figure 1. Liver histology. Left column H\&E, middle column PAS, and right column Oil Red O staining as described in methods section. All sections are at 400 $\times$ magnification $(B a r=100 \mu \mathrm{m})$. Control mice show normal hepatic architecture $(A)$ and glycogen storage patterns $(B)$ without evidence of hepatic steatosis $(A$, $C$ ). Livers from HCD-only mice had diffuse macro- and micro-vesicular stcatosis (black, red arrow, $D-F$ ) with minimal glycogen storage (green arrow, $E$ ). $\mathrm{HCD}+\mathrm{O} 3 \mathrm{FA}$-oral livers had well-preserved hepatic architecture with only rare microvacuoles in the cytoplasm of midzone hepatocytes $(G, I)$. HCD $+\mathrm{O} 3 \mathrm{FA}$-iv livers had minimal microvesicular steatosis in midzone hepatocytes $(J, L)$, and appeared to have less glycogen than HCD+O3FA-oral livers $(K)$. HCD+LIP-iv livers had severe macro- and micro-vesicular steatosis $(M, O)$ with minimal glycogen storage $(N)$.

ratio (MA:AA) >0.2. The MA:AA for HCD-only was $0.43 \pm$ 0.06 , whereas the ratios for the animals that received standard diet, HCD + O3FA-oral, HCD +O3FA-iv, and HCD + LIP-iv were $0.01 \pm 0.00,0.02 \pm 0.01$, and $0.10 \pm 0.02$, respectively.
These ratios were also demonstrated in the liver tissue fat of the studied animals (Table 2). Animals that received HCD-only also demonstrated a significant amount of de novo lipogenesis as indicated by high absolute amounts of liver palmitate (16:0), 
Table 1. Serum liver function tests

\begin{tabular}{|c|c|c|c|c|c|}
\hline & Aspartate aminotransferase & Alanine aminotransferase & Alkaline phosphatase & Total bilirubin & Direct bilirubin \\
\hline Control & $72.2 \pm 5.5$ & $48.2 \pm 3.6$ & $113.2 \pm 4.2$ & $0.10 \pm 0.02$ & $0.08 \pm 0.02$ \\
\hline HCD-only & $109.0 \pm 6.4^{*}$ & $71.6 \pm 8.2 \dagger$ & $126.0 \pm 5.9$ & $0.20 \pm 0.00 \dagger$ & $0.10 \pm 0.00$ \\
\hline $\mathrm{HCD}+\mathrm{O} 3 \mathrm{FA}$-oral & $53.0 \pm 5.8 \dagger \dagger$ & $23.0 \pm 2.6^{*}+$ & $81.8 \pm 7.2 *+$ & $0.13 \pm 0.03$ & $0.10 \pm 0.00$ \\
\hline HCD+LIP-iv & $172.4 \pm 66.4$ & $93.4 \pm 34.7$ & $88.8 \pm 9.4$ & $0.13 \pm 0.03$ & $0.10 \pm 0.00$ \\
\hline
\end{tabular}

Data are means $\pm \mathrm{SEM} ; n=5$ for each group.

$* p \leq 0.01$, statistical significance compared with control animals.

$\dagger p \leq 0.05$, statistical significance compared with control animals.

$\ddagger p \leq 0.01$, statistical significance compared with HCD-only animals.

$\S p \leq 0.05$, statistical significance compared with HCD-only animals.

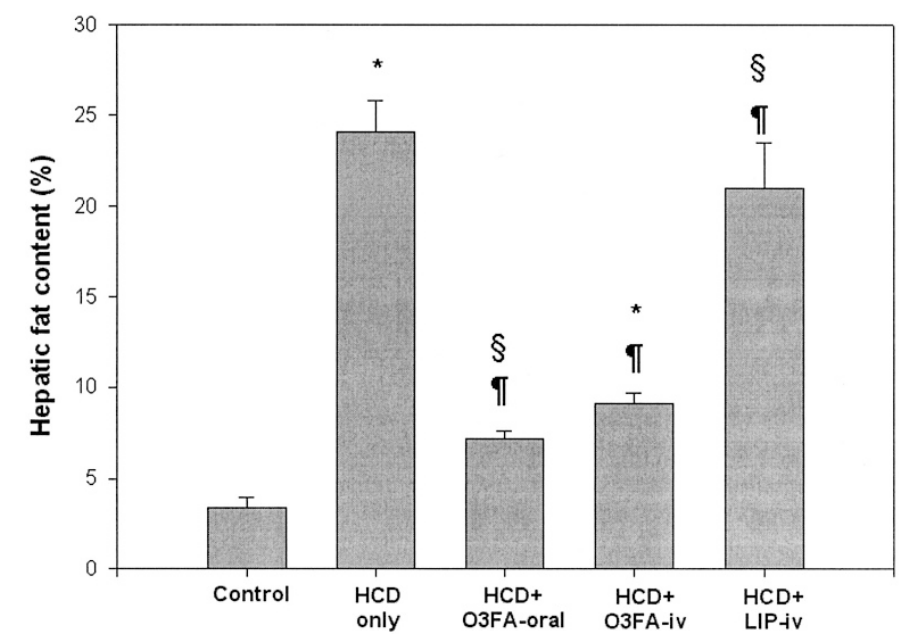

Figure 2. Hepatic fat content $(\%)$ as measured by MR-spectroscopy. The liver fat content for control mice was $3.4 \pm 0.6 \%$. Animals fed HCD-only showed an increase in liver fat content to $24.1 \pm 1.7 \%(* p \leq 0.001)$. HCD +O3FA-oral and $\mathrm{HCD}+\mathrm{O} 3 \mathrm{FA}-\mathrm{iv}$ mice had a liver fat content of $7.2 \pm 0.4$ and $9.1 \pm 0.6 \%$, respectively, both lower than HCD-only animals ( $\| p \leq 0.01$ ), but higher than control mice ( $\$ p \leq 0.05$ and $* p \leq 0.001$, respectively). Hepatic fat content from HCD+LIP-iv mice was $21.0 \pm 2.5 \%$; this was not different from HCD-only mice, but higher than control (\$), O3FA-oral- and O3FA-ivsupplemented animals. Results are expressed as mean $\pm \mathrm{SE}(n=5$ per group). (II)

palmitoleate (16:1 n-7), and oleate (18:1 n-9), compared with control animals $(36.3 \pm 2.1,12.7 \pm 0.5$, and $85.8 \pm 4.3$ $\mathrm{nmol} / \mu \mathrm{L}$ versus $4.6 \pm 0.6,0.9 \pm 0.1$, and $6.1 \pm 0.7 \mathrm{nmol} / \mu \mathrm{L}$, respectively; $p \leq 0.001$ ). The total liver fat content of HCDonly-fed livers as determined by fatty acid analysis was also significantly higher than in control animals $(137.9 \pm 5.5$ versus $16.7 \pm 2.1 \mathrm{nmol} / \mathrm{mg} ; p \leq 0.001)$. As expected, the molar percentage of the O3FA eicosapentaenoic acid (20:5 n-3) and docosahexaenoic acid (22:6n-3) in the livers of control (0.7 \pm 0.1 and $4.2 \pm 0.3$, respectively), HCD + O3FA-oral $(0.6 \pm 0.1$ and $3.3 \pm 0.4$, respectively), and $\mathrm{HCD}+\mathrm{O} 3 \mathrm{FA}$-iv $(0.5 \pm 0.1$ and $3.9 \pm 0.4$, respectively) animals are similar, whereas the percentages in the HCD-only $(0.0 \pm 0.0$ and $0.2 \pm 0.0$, respectively) and HCD-LIP-iv $(0.0 \pm 0.0$ and $0.9 \pm 0.4$, respectively) are significantly lower ( $p \leq 0.05$ ). It is interesting that the relative amounts of serum arachidonic acid in these groups were significantly higher than in the control and O3FAsupplemented animals $(p \leq 0.05)$ suggesting a potential for a greater degree of inflammation.

\section{DISCUSSION}

We show that supplementation of O3FAs can prevent the occurrence of dietary-induced hepatic steatosis in a murine model of total parenteral nutrition. This model results in severe steatotic damage to the liver within $19 \mathrm{~d}$ and is accompanied by essential fatty acid deficiency and enhanced de novo lipogenesis (45). The liver injury that is observed in this model is essentially identical to that seen in conventional rodent models that use i.v. parenteral nutrition. However, this model is unique in that it is easy to manage and, because there are no i.v. catheters present, interpretation of data is not confounded by catheter sepsis seen in other models that are dependent on i.v. access where parenteral nutrition can be administered reliably for only $7 \mathrm{~d}(47,48)$. Furthermore, this model enables us to study specifically the roles of lipid solutions in parenteral nutrition-induced hepatic steatosis and allows for potential use of genetically modified animals to examine specific molecular mechanisms of such injury. The caloric intake of mice on this regimen is sufficient to satisfy established dietary energy needs. We emphasize that the amount of lipid that was supplemented, either as O3FAs or as Intralipid, did not affect satiety in these animals as the daily per-animal intake of the HCD averaged 15 $\mathrm{mL}$ for all experimental groups; this corresponded to $\sim 450 \mathrm{kcal}$ $\cdot \mathrm{kg}^{-1} \cdot \mathrm{d}^{-1}$, a caloric load similar to the established dietary energy needs of the mouse (49). Furthermore, because all animals gained appropriate weight compared with control animals, it seems that the supplemented lipids did not contribute substantially to the total caloric intake in these animals.

Our results demonstrate that O3FA supplementation, both orally and intravenously, but not i.v. supplementation of a standard lipid emulsion can attenuate hepatic steatosis in mice. It has been well described that essential fatty acid deficiency alone can cause fatty changes of the liver (50) and that reversing essential fatty acid deficiency can prevent hepatic steatosis (51). Although our model produces essential fatty acid deficiency, we have shown that the beneficial effect that O3FA supplementation has on hepatic steatosis is not solely due to the reversal of essential fatty acid deficiency in these mice, which both routes of administration of O3FAs were able to accomplish through their small but important content of arachidonic acid. In this study, we demonstrated that animals that received the HCD supplemented with a standard i.v. lipid emulsion (HCD+LIP-iv group) developed severe hepatic steatosis, similar to HCD-only as demonstrated by histology, magnetic resonance imaging liver fat content data, and liver 
Table 2. Fatty acid (triglycerides) composition of serum and liver

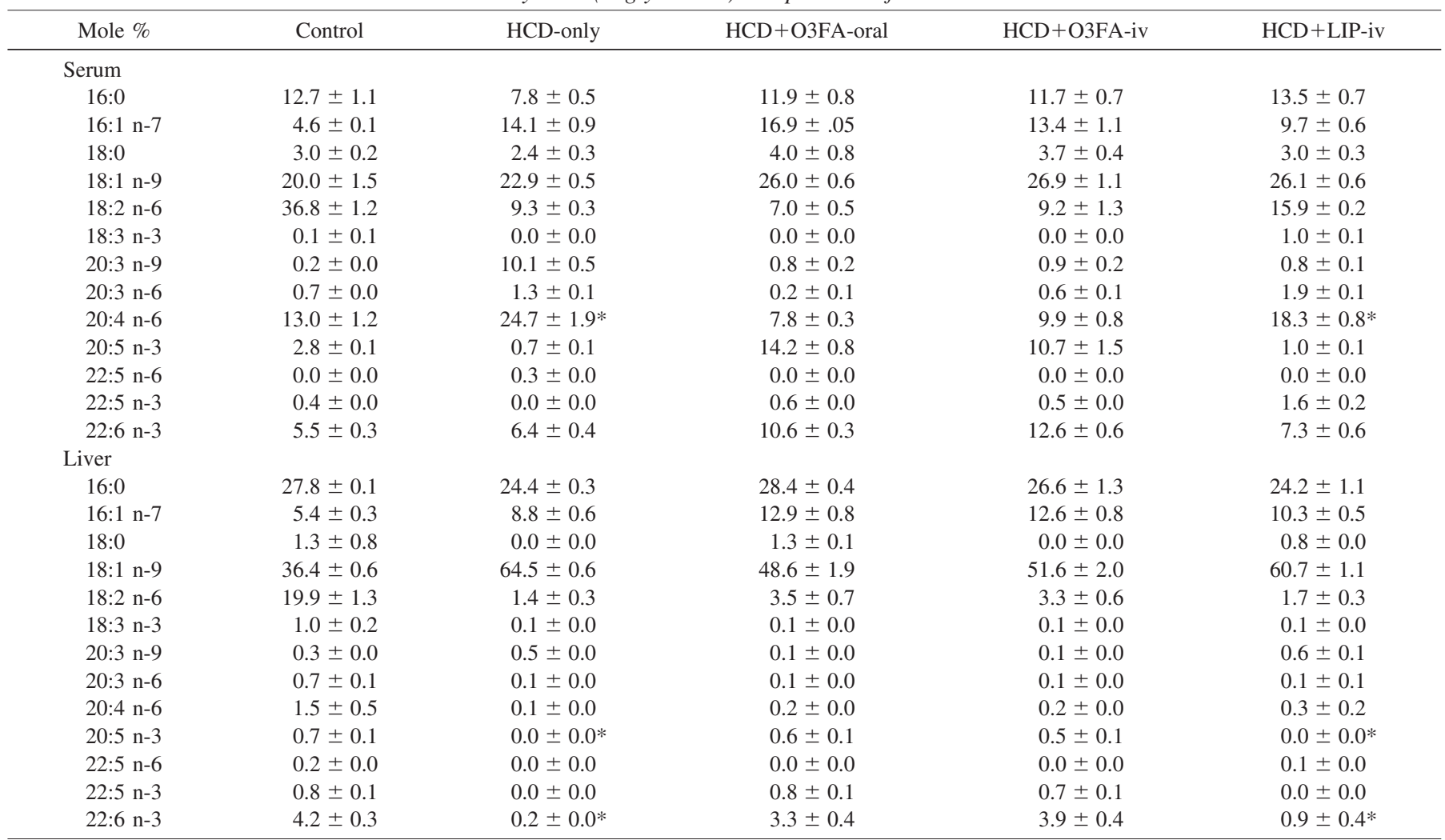

$* p \leq 0.05$, statistical significance compared with control, HCD+O3FA-oral, and HCD+O3FA-iv animals.

function tests. These animals, however, are not essential fatty acid deficient, because they are provided with substantial quantities of the essential fatty acid linoleic. In contrast, animals that received the HCD supplemented by i.v. O3FAs and also those that were supplemented through the orogastric route did not develop fatty changes of the liver. These data suggest that the content or perhaps the ratio of omega-6:omega-3 fatty acids, not the essential fatty acid status, is paramount in preventing hepatic steatosis in this model. It has been shown that a high polyunsaturated omega-6:omega-3 long-chain fatty acid ratio is associated with nonalcoholic fatty liver disease and may favor lipid synthesis over oxidation and secretion (43). The standard lipid emulsion that we administered had a 15times higher polyunsaturated omega-6:omega-3 fatty acid ratio compared with the O3FA emulsion and 11 times higher than the normal diet (data not shown).

The source of the hepatic lipid was not determined in this study, but the locations are suggestive. With HCD-only, the lipid was found primarily in the portal area, suggesting that this is the primary site of de novo lipogenesis, because exogenous fat was not provided. With HCD+LIP-iv, both the portal area and the central vein had increases in fat, as determined by histology. Although not proved, this suggests that the fat that was found adjacent to the central vein was the fat that was administered. The source of the fat in the portal area in this group could also be the administered fat, suggesting a reduction or elimination of de novo lipogenesis, or, conversely, could represent the product of continued de novo lipogenesis that was not prevented by the i.v. administration of a high linoleic acid-containing fat, perhaps as a result of altered hepatic metabolism of these artificial chylomicra. Only further studies will distinguish between these two possibilities.

Multiple reports in the literature have recognized that supplementation of lipid emulsions may be a factor in the development of fatty livers as a result of total parenteral nutrition. In 1982, Allardyce (52) described a cohort of 35 patients who received total parenteral nutrition with conventional lipid emulsions for $>3 \mathrm{wk}$ and concluded that the symptoms of cholestasis in these patients recovered when the lipid supplementation was reduced. These data were corroborated by other clinical observations $(44,53-55)$ and in animal models (56). A study by Zaman et al. (57) demonstrated that isolated perfusion of rat livers with total parenteral nutrition that was supplemented with Intralipid led to more steatosis and poorer liver function than livers that were perfused with parenteral nutrition only. Potential mechanisms include the accumulation of lipid metabolites in hepatic sinusoidal macrophages, thereby interfering with the clearance of bacteria and their products. Furthermore, it has been proposed that standard lipid emulsions may enhance the production of proinflammatory cytokines, because they are a relatively rich source of omega- 6 fatty acids, precursors to arachidonic acid $(36,58)$.

The notion that O3FAs may be beneficial in hepatic injury is not novel. Chen et al. $(32,41,56)$ described the effects that various fatty acid compositions had on rats that received total parenteral nutrition. They demonstrated that emulsions that were derived from fish oil and were high in O3FAs led to a lower hepatic fat content in rats that received total parenteral nutrition than emulsions that were derived from olive and safflower oils. Although a mechanism for the beneficial effects 
of O3FA supplementation is not provided in these studies, several hypotheses have since been put forward. O3FAs may stimulate both peroxisomal and mitochondrial $\beta$-oxidation of fatty acids, thereby decreasing the availability of nonesterified fatty acids as substrates for triacylglycerol synthesis and secretion (59-61). In addition, O3FAs have been shown to reduce the activity of acetyl CoA carboxylase and thereby inhibit de novo lipogenesis in rat livers (60). Other mechanisms include lowering the activity of superoxide dismutase and glutathione peroxidase (40), the property of O3FAs to act as suboptimal substrates for esterification to glycerol $(62,63)$, and reducing the synthesis of arachidonic acid by inhibiting the activities of omega-6- and omega-5 desaturases on linoleic acid in the liver (64). It seems likely that O3FAs exert their beneficial effect in lowering hepatic fat content through a combination of these mechanisms.

In conclusion, we have demonstrated that enteral and i.v. supplementation of O3FAs can ameliorate hepatic steatosis in a murine model of parenteral nutrition as demonstrated by histology, MRS, serum liver function tests, and serum and liver fatty acid analysis. In contrast, supplementation with the standard i.v. lipid emulsion Intralipid does not improve the fatty liver changes in these animals. Because i.v. lipid supplementation is a key component of nutritional support in patients who receive total parenteral nutrition, further studies into the mechanisms of these effects and the potential substitution of standard lipid emulsions with O3FA-containing emulsions in these patients are warranted.

\section{REFERENCES}

1. Angulo P 2002 Nonalcoholic fatty liver disease. N Engl J Med 346:1221-1231

2. Clark JM, Brancati FL, Diehl AM 2002 Nonalcoholic fatty liver disease. Gastroenterology 122:1649-1657

3. Clark JM, Diehl AM 2003 Defining nonalcoholic fatty liver disease: implications for epidemiologic studies. Gastroenterology 124:248-250

4. Teli MR, James OF, Burt AD, Bennett MK, Day CP 1995 The natural history of nonalcoholic fatty liver: a follow-up study. Hepatology 22:1714-1719

5. Clark JM, Brancati FL, Diehl AM 2003 The prevalence and etiology of elevated aminotransferase levels in the United States. Am J Gastroenterol 98:960-967

6. Bellentani S, Saccoccio G, Masutti F, Croce LS, Brandi G, Sasso F, Cristanini G, Tiribelli C 2000 Prevalence of and risk factors for hepatic steatosis in Northern Italy. Ann Intern Med 132:112-117

7. Wanless IR, Lentz JS 1990 Fatty liver hepatitis (steatohepatitis) and obesity: an autopsy study with analysis of risk factors. Hepatology 12:1106-1110

8. Ratziu V, Giral P, Charlotte F, Bruckert E, Thibault V, Theodorou I, Khalil L, Turpin G, Opolon P, Poynard T 2000 Liver fibrosis in overweight patients. Gastroenterology 118:1117-1123

9. Ruderman N, Chisholm D, Pi-Sunyer X, Schneider S 1998 The metabolically obese, normal-weight individual revisited. Diabetes 47:699-713

10. Clark JM, Diehl AM 2002 Hepatic steatosis and type 2 diabetes mellitus. Curr Diab Rep 2:210-215

11. Sahoo S, Hart J 2003 Histopathological features of L-asparaginase-induced liver disease. Semin Liver Dis 23:295-299

12. Kooby DA, Fong Y, Suriawinata A, Gonen M, Allen PJ, Klimstra DS, DeMatteo RP, D'Angelica M, Blumgart LH, Jarnagin WR 2003 Impact of steatosis on perioperative outcome following hepatic resection. J Gastrointest Surg 7:1034-1044

13. Sax HC, Talamini MA, Brackett K, Fischer JE 1986 Hepatic steatosis in total parenteral nutrition: failure of fatty infiltration to correlate with abnormal serum hepatic enzyme levels. Surgery 100:697-704

14. Sax HC, Bower RH 1988 Hepatic complications of total parenteral nutrition. JPEN J Parenter Enteral Nutr 12:615-618

15. Hughes CA, Talbot IC, Ducker DA, Harran MJ 1983 Total parenteral nutrition in infancy: effect on the liver and suggested pathogenesis. Gut 24:241-248

16. Benjamin DR 1981 Hepatobiliary dysfunction in infants and children associated with long-term total parenteral nutrition. A clinico-pathologic study. Am J Clin Pathol 76:276-283

17. Mullick FG, Moran CA, Ishak KG 1994 Total parenteral nutrition: a histopathologic analysis of the liver changes in 20 children. Mod Pathol 7:190-194

18. Levine A, Maayan A, Shamir R, Dinari G, Sulkes J, Sirotta L 1999 Parenteral nutrition-associated cholestasis in preterm neonates: evaluation of ursodeoxycholic acid treatment. J Pediatr Endocrinol Metab 12:549-553
19. Kaufman SS 2002 Prevention of parenteral nutrition-associated liver disease in children. Pediatr Transplant 6:37-42

20. Day CP, James OF 1998 Steatohepatitis: a tale of two "hits"? Gastroenterology 114:842-845

21. Day CP 2002 Pathogenesis of steatohepatitis. Best Pract Res Clin Gastroenterol 16:663-678

22. Helms RA, Miller JL, Burckart GJ, Allen RG 1983 Clinical outcome as assessed by anthropometric parameters, albumin, and cellular immune function in high-risk infants receiving parenteral nutrition. J Pediatr Surg 18:564-569

23. Moss RL, Das JB, Raffensperger JG 1993 Total parenteral nutrition-associated cholestasis: clinical and histopathologic correlation. J Pediatr Surg 28:1270-1274; discussion 1274-1275

24. Moss RL, Haynes AL, Pastuszyn A, Glew RH 1999 Methionine infusion reproduces liver injury of parenteral nutrition cholestasis. Pediatr Res 45:664-668

25. Su KP, Huang SY, Chiu CC, Shen WW 2003 Omega-3 fatty acids in major depressive disorder. A preliminary double-blind, placebo-controlled trial. Eur Neuropsychopharmacol 13:267-271

26. Freeman MP 2000 Omega-3 fatty acids in psychiatry: a review. Ann Clin Psychiatry 12:159-165

27. Arvindakshan M, Ghate M, Ranjekar PK, Evans DR, Mahadik SP 2003 Supplementation with a combination of omega-3 fatty acids and antioxidants (vitamins E and C) improves the outcome of schizophrenia. Schizophr Res 62:195-204

28. Mata Lopez P, Ortega RM 2003 Omega-3 fatty acids in the prevention and control of cardiovascular disease. Eur J Clin Nutr 57:S22-S25

29. Leaf A, Kang JX, Xiao YF, Billman GE 2003 Clinical prevention of sudden cardiac death by $n-3$ polyunsaturated fatty acids and mechanism of prevention of arrhythmias by n-3 fish oils. Circulation 107:2646-2652

30. Simopoulos AP 2002 Omega-3 fatty acids in inflammation and autoimmune diseases. J Am Coll Nutr 21:495-505

31. De Vizia B, Raia V, Spano C, Pavlidis C, Coruzzo A, Alessio M 2003 Effect of an 8-month treatment with omega-3 fatty acids (eicosapentaenoic and docosahexaenoic) in patients with cystic fibrosis. JPEN J Parenter Enteral Nutr 27:52-57

32. Chen MF, Lee YT, Hsu HC, Yeh PC, Liau CS, Huang PC 1992 Effects of dietary supplementation with fish oil on prostanoid metabolism during acute coronary occlusion with or without reperfusion in diet-induced hypercholesterolemic rabbits. Int J Cardiol 36:297-304

33. Novak TE, Babcock TA, Jho DH, Helton WS, Espat NJ 2003 NF-kappa B inhibition by omega-3 fatty acids modulates LPS-stimulated macrophage TNF-alpha transcription. Am J Physiol 284:L84-L89

34. Babcock TA, Novak T, Ong E, Jho DH, Helton WS, Espat NJ 2002 Modulation of lipopolysaccharide-stimulated macrophage tumor necrosis factor-alpha production by omega- 3 fatty acid is associated with differential cyclooxygenase- 2 protein expression and is independent of interleukin-10. J Surg Res 107:135-139

35. Mayer K, Merfels M, Muhly-Reinholz M, Gokorsch S, Rosseau S, Lohmeyer J, Schwarzer N, Krull M, Suttorp N, Grimminger F, Seeger W 2002 Omega-3 fatty acids suppress monocyte adhesion to human endothelial cells: role of endothelial PAF generation. Am J Physiol 283:H811-H818

36. Mayer K, Meyer S, Reinholz-Muhly M, Maus U, Merfels M, Lohmeyer J, Grimminger F, Seeger W 2003 Short-time infusion of fish oil-based lipid emulsions, approved for parenteral nutrition, reduces monocyte proinflammatory cytokine generation and adhesive interaction with endothelium in humans. J Immunol 171:4837-4843

37. Rallidis LS, Paschos G, Liakos GK, Velissaridou AH, Anastasiadis G, Zampelas A 2003 Dietary alpha-linolenic acid decreases C-reactive protein, serum amyloid A and interleukin-6 in dyslipidaemic patients. Atherosclerosis 167:237-242

38. Park Y, Harris WS 2003 Omega-3 fatty acid supplementation accelerates chylomicron triglyceride clearance. J Lipid Res 44:455-463

39. Van Aerde JE, Duerksen DR, Gramlich L, Meddings JB, Chan G, Thomson AB, Clandinin MT 1999 Intravenous fish oil emulsion attenuates total parenteral nutritioninduced cholestasis in newborn piglets. Pediatr Res 45:202-208

40. Yeh SL, Chang KY, Huang PC, Chen WJ 1997 Effects of n-3 and n-6 fatty acids on plasma eicosanoids and liver antioxidant enzymes in rats receiving total parenteral nutrition. Nutrition 13:32-36

41. Chen WJ, Yeh SL 2003 Effects of fish oil in parenteral nutrition. Nutrition 19:275-279

42. Sekiya M, Yahagi N, Matsuzaka T, Najima Y, Nakakuki M, Nagai R, Ishibashi S, Osuga J, Yamada N, Shimano H 2003 Polyunsaturated fatty acids ameliorate hepatic steatosis in obese mice by SREBP-1 suppression. Hepatology 38:1529-1539

43. Araya J, Rodrigo R, Videla LA, Thielemann L, Orellana M, Pettinelli P, Poniachik J 2004 Increase in long-chain polyunsaturated fatty acid $n-6 / n-3$ ratio in relation to hepatic steatosis in non-alcoholic fatty liver disease patients. Clin Sci (Lond) 106:635-643

44. Colomb V, Jobert-Giraud A, Lacaille F, Goulet O, Fournet JC, Ricour C 2000 Role of lipid emulsions in cholestasis associated with long-term parenteral nutrition in children. JPEN J Parenter Enteral Nutr 24:345-350

45. Alwayn IP, Javid PJ, Gura KM, Nose V, Ollero M, Puder M 2004 Do polyunsaturated fatty acids ameliorate hepatic steatosis in obese mice by SREPB-1 suppression or by correcting essential fatty acid deficiency? Hepatology 39:1176-1177; author reply 1177-1178

46. Alvarez JG, Touchstone JC 1992 Separation of acidic and neutral lipids by aminopropyl-bonded silica gel column chromatography. J Chromatogr 577:142-145

47. Yang H, Finaly R, Teitelbaum DH 2003 Alteration in epithelial permeability and ion transport in a mouse model of total parenteral nutrition. Crit Care Med 31:1118-1125

48. Ohta K, Omura K, Hirano K, Kanehira E, Ishikawa N, Kato Y, Kawakami K, Watanabe G 2003 The effects of an additive small amount of a low residual diet against total parenteral nutrition-induced gut mucosal barrier. Am J Surg 185:79-85

49. Reeves PG, Nielsen FH, Fahey GC Jr 1993 AIN-93 purified diets for laboratory rodents: final report of the American Institute of Nutrition ad hoc writing committee on the reformulation of the AIN-76A rodent diet. J Nutr 123:1939-1951 
50. Keim NL, Mares-Perlman JA 1984 Development of hepatic steatosis and essential fatty acid deficiency in rats with hypercaloric, fat-free parenteral nutrition. J Nutr 114:1807-1815

51. Goheen SC, Larkin EC, Rao GA 1983 Severe fatty liver in rats fed a fat-free ethanol diet, and its prevention by small amounts of dietary arachidonate. Lipids 18:285-290

52. Allardyce DB 1982 Cholestasis caused by lipid emulsions. Surg Gynecol Obstet 154:641-647

53. Cavicchi M, Crenn P, Beau P, Degott C, Boutron MC, Messing B 1998 Severe live complications associated with long-term parenteral nutrition are dependent on lipid parenteral input. Transplant Proc 30:2547

54. Cavicchi M, Beau P, Crenn P, Degott C, Messing B 2000 Prevalence of liver disease and contributing factors in patients receiving home parenteral nutrition for permanent intestinal failure. Ann Intern Med 132:525-532

55. Clayton PT, Whitfield P, Iyer K 1998 The role of phytosterols in the pathogenesis of liver complications of pediatric parenteral nutrition. Nutrition 14:158-164

56. Chen WJ, Yeh SL, Huang PC 1996 Effects of fat emulsions with different fatty acid composition on plasma and hepatic lipids in rats receiving total parenteral nutrition. Clin Nutr 15:24-28

57. Zaman N, Tam YK, Jewell LD, Coutts RT 1997 Effects of intravenous lipid as a source of energy in parenteral nutrition associated hepatic dysfunction and lidocaine elimination: a study using isolated rat liver perfusion. Biopharm Drug Dispos $18: 803-819$
58. Fernandes G 1994 Dietary lipids and risk of autoimmune disease. Clin Immunol Immunopathol 72:193-197

59. Burdge GC, Finnegan YE, Minihane AM, Williams CM, Wootton SA 2003 Effect of altered dietary n-3 fatty acid intake upon plasma lipid fatty acid composition, conversion of [13C]alpha-linolenic acid to longer-chain fatty acids and partitioning towards beta-oxidation in older men. Br J Nutr 90:311-321

60. Neschen S, Moore I, Regittnig W, Yu CL, Wang Y, Pypaert M, Petersen KF, Shulman GI 2002 Contrasting effects of fish oil and safflower oil on hepatic peroxisomal and tissue lipid content. Am J Physiol 282:E395-E401

61. Willumsen N, Hexeberg S, Skorve J, Lundquist M, Berge RK 1993 Docosahexaenoic acid shows no triglyceride-lowering effects but increases the peroxisomal fatty acid oxidation in liver of rats. J Lipid Res 34:13-22

62. Rustan AC, Nossen JO, Christiansen EN, Drevon CA 1988 Eicosapentaenoic acid reduces hepatic synthesis and secretion of triacylglycerol by decreasing the activity of acyl-coenzyme A:1,2-diacylglycerol acyltransferase. J Lipid Res 29:1417-1426

63. Nossen JO, Rustan AC, Gloppestad SH, Malbakken S, Drevon CA 1986 Eicosapentaenoic acid inhibits synthesis and secretion of triacylglycerols by cultured rat hepatocytes. Biochim Biophys Acta 879:56-65

64. Bellenger J, Bellenger S, Clement L, Mandard S, Diot C, Poisson JP, Narce M 2004 A new hypotensive polyunsaturated fatty acid dietary combination regulates oleic acid accumulation by suppression of stearoyl CoA desaturase 1 gene expression in the SHR model of genetic hypertension. FASEB J 18:773-775

\section{Erratum}

The article, "Effect of Dietary Ribonucleotides on Infant Immune Status. Part 1: Humoral Responses," by Joseph P. Schaller, Matthew J. Kuchan, Debra L. Thomas, Christopher T. Cordle, Timothy R. Winship, Rachael H. Buck, Geraldine E. Baggs, and J. Gary Wheeler (Pediatric Research 56: 883-890), contained several errors.

On page 886, right column, paragraph 1, the sentence beginning "Comparison of the RCFD" should read: Comparison of the RCFD curves revealed statistically significant distribution differences only at 12 -mo (FN different from F, $\mathrm{p}=0.023$ ) using the Kolmogorov-Smirnov test (30).

On page 887, the third footnote in Table 3 should read: Different by a post hoc three-group RMA on the evaluable data subset for 6, 7, and 12 mo group $\mathrm{X}$ time interaction $\mathrm{p}=0.0285$.

On page 888, for the legend of Figure 1, the sentence beginning "Reverse cumulative distributions" should read: Reverse cumulative distributions were different at 12 mo (IIFN $>\mathrm{F}, \mathrm{p}=0.023$ ).

On page 889 , right column, paragraph 2, the sentence beginning "In this regard, " should read: In this regard, it is most interesting that significant differences in key indicators of immune function (poliovirus VN1 responses and subsets of T and NK cells) were identified not only between formula groups but also more often between breast-fed infants and those fed formula without ribonucleotides.

Table 2 had missing percentage values and is reprinted below.

Table 2. Demographic Variables in the F, FN, and HMF Groups*

\begin{tabular}{|c|c|c|c|}
\hline & $\mathrm{F}$ & FN & HMF \\
\hline Subjects, $n(\%)$ & 147 & 138 & 192 \\
\hline Male & $62(42)$ & $61(44)$ & $104(54)$ \\
\hline Female & $85(58)$ & $77(56)$ & $88(46)$ \\
\hline Caucasian & $126(85.7)$ & $119(86.2)$ & $170(88.5)$ \\
\hline African-American & $14(9.5)$ & $14(10.1)$ & $12(6.3)$ \\
\hline Hispanic & $1(0.7)$ & $1(0.7)$ & $4(2.1)$ \\
\hline Gestational age $(w k) \dagger$ & 39 & 39 & 39 \\
\hline \multicolumn{4}{|c|}{ Weight $(\mathrm{g})$ at $10 \mathrm{~d}$ of age } \\
\hline Male & $3528 \pm 66$ & $3561 \pm 67$ & $3625 \pm 51$ \\
\hline Female & $3535 \pm 59$ & $3397 \pm 48$ & $3509 \pm 49$ \\
\hline \multicolumn{4}{|c|}{ Maternal education, $n(\%)$} \\
\hline Some high school & $11(8)$ & $9(7)$ & $5(3)$ \\
\hline
\end{tabular}

* F, control; FN, ribonucleotide-supplemented; HMF, fed exclusively human milk for at least 2 months followed by human milk or commercial Similac with Iron at weaning.

$\dagger$ Values are mean [median].

$\ddagger$ Values are mean \pm SEM. 